\title{
Association between Intraoperative End-Tidal Carbon Dioxide and Postoperative Nausea and Vomiting in Gynecologic Laparoscopic Surgery
}

\section{Li Dong}

Kyoto University Hospital

\section{Chikashi Takeda}

Kyoto University Hospital

Hajime Yamazaki

Kyoto University

\section{Miho Hamada}

Kyoto University Hospital

\section{Akiko Hirotsu}

Kyoto University Hospital

Yosuke Yamamoto

Kyoto University

Toshiyuki Mizota ( $\nabla$ mizota@kuhp.kyoto-u.ac.jp )

Kyoto University Hospital

\section{Research Article}

Keywords: EtCO2, gynecologic laparoscopy, postoperative nausea and vomiting, laparoscopy, postoperative length of hospital stay

Posted Date: February 3rd, 2022

DOI: https://doi.org/10.21203/rs.3.rs-1313239/v1

License: (a) (1) This work is licensed under a Creative Commons Attribution 4.0 International License. Read Full License 


\section{Abstract \\ PURPOSE}

Gynecologic laparoscopic surgery has a high incidence of postoperative nausea and vomiting (PONV). Studies suggest that low intraoperative end-tidal carbon dioxide $\left(\mathrm{EtCO}_{2}\right)$ is associated with an increased incidence of PONV, but the results have not been consistent among studies. This study investigated the association between intraoperative $\mathrm{EtCO}_{2}$ and $\mathrm{PONV}$ in patients undergoing gynecologic laparoscopic surgeries under general anesthesia.

\section{METHODS}

This retrospective cohort study involved patients who underwent gynecologic laparoscopic surgeries under general anesthesia at Kyoto University Hospital. We defined hypocapnia as a mean $\mathrm{EtCO}_{2}$ of $<35$ $\mathrm{mmHg}$. Multivariable modified Poisson regression analysis examined the association between low $\mathrm{EtCO}_{2}$ and PONV two days after surgery and the postoperative length of hospital stay (PLOS).

\section{RESULTS}

Of the 739 patients, $120(16 \%)$ had low $\mathrm{EtCO}_{2}$, and 430 (58\%) developed PONV two days after surgery. There was no substantial association between low $\mathrm{EtCO}_{2}$ and increased incidence of PONV (adjusted risk ratio: $0.96 ; 95 \%$ confidence interval [Cl]: $0.80-1.14 ; p=0.658$ ). Furthermore, there was no substantial association between low $\mathrm{EtCO}_{2}$ and prolonged PLOS (adjusted difference in PLOS: $0.13 ; 95 \% \mathrm{Cl},-1.00$ to $1.28 ; p=0.816)$.

\section{CONCLUSION}

Intraoperative low $\mathrm{EtCO}_{2}$ was not substantially associated with either increased incidence of PONV or prolonged PLOS.

\section{Introduction}

The incidence of postoperative nausea and vomiting (PONV) remains high despite considerable improvements in treatment over the past few decades. PONV is nausea or vomiting in the first 24 to $48 \mathrm{~h}$ after surgery ${ }^{1}$. Well-established risk factors for PONV include female gender, history of PONV or motion sickness, nonsmoking, and postoperative opioid use ${ }^{2}$. The risk of PONV is up to $80 \%$ in high-risk patients with all four risk factors ${ }^{3}$. The incidence of PONV is particularly high among patients undergoing gynecologic laparoscopic surgery ${ }^{4}$. PONV is associated with decreased patient satisfaction ${ }^{5}$, increased postoperative complications ${ }^{6}$, and longer postoperative length of hospital stay (PLOS) ${ }^{7}$. 
Hypocapnia may be associated with decreased systemic vasodilation ${ }^{8}$ and may cause tissue ischemia ${ }^{9}$, intestinal ischemia ${ }^{10}$, and cerebral ischemia ${ }^{11,12}$. Animal studies have reported that serotonin levels in the brain, a highly emetogenic substance, increase with intestinal ${ }^{13,14}$ and cerebral ischemia ${ }^{15}$. Based on the hypothesis associating hypocapnia with increased serotonin levels due to intestinal and cerebral ischemia, studies associate intraoperative hypocapnia with increased incidence of PONV ${ }^{16,17}$. However, the relationship between hypocapnia and PONV remains unclear because some studies had conflicting results $^{18,19}$.

Therefore, we examined the association between intraoperative end-tidal carbon dioxide $\left(\mathrm{EtCO}_{2}\right)$ and the incidence of PONV in patients undergoing gynecologic laparoscopic surgery. We adjusted for important confounding factors and assessed the effects of the duration and severity of low $\mathrm{EtCO}_{2}$ exposure.

\section{Methods}

\section{Ethics}

The Certified Review Board of Kyoto University, Kyoto, Japan (Chairperson Prof. Shinji Kosugi) approved the protocol for this study (approval no.: R1272-3, January 23, 2020). Additionally, the informed consent requirement was waived due to this study's retrospective nature.

\section{Study design, setting, and population}

In this single-center retrospective cohort study, we used data from the Kyoto University Hospital IMProve Anaesthesia Care and ouTcomes (Kyoto-IMPACT) database. The Kyoto-IMPACT database aims to clarify the relationship between intraoperative respiratory and cardiovascular parameters and postoperative outcomes. We consecutively selected patients who underwent surgery under the care of anesthesiologists at Kyoto University Hospital (1,121 beds). We have published several studies using the Kyoto-IMPACT database ${ }^{20,21}$. We included adult female patients aged 18 years or older who underwent gynecologic laparoscopic surgery (i.e., adnexal surgery and/or hysterectomy) at Kyoto University Hospital between January 2012 and December 2017. The gynecologic laparoscopic surgery population was selected because the predicted incidence rate of PONV in this population is $30 \%-$ $40 \%$, assumed to be a medium risk of PONV ${ }^{4}$. The exclusion criteria were as follows: 1 ) patients with postoperative intensive care unit admission; 2) those who underwent multiple surgeries

within one week during the study period; 3 ) those who received epidural anesthesia; 4) those with missing smoking data, and 5) those with missing intraoperative $\mathrm{EtCO}_{2}$ data.

\section{Data collection}

We collected data from the anesthesia information management and electronic medical record systems and constructed the Kyoto-IMPACT database. $\mathrm{EtCO}_{2}$ was continuously measured using a sidestream gas analyzer (GF-220R Multigas/Flow Unit, Nihon Kohden ${ }^{\circledR}$, Japan) that was automatically 
uploaded to the anesthesia information management system every $60 \mathrm{~s}$. Intraoperative $\mathrm{EtCO}_{2}$ was the mean $\mathrm{EtCO}_{2}$ level from skin incision to skin closure. We removed $\mathrm{EtCO}_{2}$ levels lower than $20 \mathrm{mmHg}$ as artifacts ( $\mathrm{EtCO}_{2}$ during aspiration or position change). The definitions of variables, including the minimum and maximum $\mathrm{EtCO}_{2}$ levels, can be found in Supplementary Data Table S1. We collected data on PONV by reviewing all clinical data contained in the electronic medical records. Ward nurses assessed the presence of nausea and vomiting at least twice daily. We defined PONV as one or more episodes of nausea or vomiting during the first two days after surgery and vomiting as one or more episodes of vomiting during the same period.

\section{Exposure}

To determine how $\mathrm{EtCO}_{2}$ affects PONV, we defined exposure by calculating the dose, time, and cumulative effects of $\mathrm{EtCO}_{2}$. First, we evaluated the dose effects of $\mathrm{EtCO}_{2}$ using the mean $\mathrm{EtCO}_{2}$. Next, we divided the patients into two groups based on the cutoff $\mathrm{EtCO}_{2}$ level of $35 \mathrm{mmHg}$ proposed by Way and $\mathrm{Hill}^{22}$. We defined low $\mathrm{EtCO}_{2}$ as a mean $\mathrm{EtCO}_{2}$ lower than $35 \mathrm{mmHg}$ and normal $\mathrm{EtCO}_{2}$ as a mean $\mathrm{EtCO}_{2}$ greater than or equal to $35 \mathrm{mmHg}$. We classified the patients in either of these groups and used them as the primary exposure for further analysis. Additionally, we categorized the mean $\mathrm{EtCO}_{2}$ levels into quartiles (i.e., $<35,35-37,37-40$, and $\geq 40 \mathrm{mmHg}$ ) because the relationship between $\mathrm{EtCO}_{2}$ and PONV might not be linear. To assess the effects of the duration and severity of low $\mathrm{EtCO}_{2}$ exposure, we determined the time effect based on the minutes when the $\mathrm{EtCO}_{2}$ level was below $35 \mathrm{mmHg}$ and measured the cumulative effect as the area with $\mathrm{EtCO}_{2}$ levels below the threshold of $35 \mathrm{mmHg}$ for each patient. Furthermore, we categorized the minutes and area under the threshold of an $\mathrm{EtCO}_{2}$ level of $35 \mathrm{mmHg}$ into quartiles; the lowest quartile was the reference category.

\section{Outcomes}

The primary outcome in this study was PONV, defined as PONV for two days postoperatively. The secondary outcomes were nausea for two days postoperatively, vomiting for two days postoperatively, PONV for 3-7 days postoperatively, and PLOS. We defined PLOS as the duration of hospital stay after surgery for patients who survived until discharge.

\section{Statistical analysis}

We analyzed the relationship between intraoperative $\mathrm{EtCO}_{2}$ and $\mathrm{PONV}$ before data collection. We used the Mann-Whitney test for group comparisons, and continuous variables were expressed as the median and interquartile range (IQR), and categorical variables were expressed as counts and percentages (\%).

First, we performed modified Poisson regression analysis with robust variance to calculate the risk ratio for low $\mathrm{EtCO}_{2}$ (mean $\mathrm{EtCO}_{2}$ of less than $35 \mathrm{mmHg}$ ) and $\mathrm{PONV}$, with the reference category of normal $\mathrm{EtCO}_{2}$ (mean $\left.\mathrm{EtCO}_{2} \geq 35 \mathrm{mmHg}\right)^{23}$. Additionally, we calculated the risk ratios of the mean $\mathrm{EtCO}_{2}$ level in 
the first quartile (mean $\mathrm{EtCO}_{2}$ of less than $35 \mathrm{mmHg}$ ), third quartile (mean $\mathrm{EtCO}_{2}$ of $37-40 \mathrm{mmHg}$ ), and fourth quartile (mean $\mathrm{EtCO}_{2}$ of more than or equal to $40 \mathrm{mmHg}$ ). The second quartile (mean $\mathrm{EtCO}_{2}$ of $35-37 \mathrm{mmHg}$ ) was the reference category because it was considered normocapnia. Furthermore, we examined the time and cumulative effects of $\mathrm{EtCO}_{2}$ by evaluating how each quartile affected PONV, with the first quartile (with minutes under an $\mathrm{EtCO}_{2}$ of $35 \mathrm{mmHg}$ and the area below the threshold of 35 $\mathrm{mmHg}$ ) being the reference category. We created a model using the covariates previously used to demonstrate the relationship between intraoperative $\mathrm{EtCO}_{2}$ and $\mathrm{PONV}$. The model included age, smoking history, surgery duration, body mass index (BMI), total intravenous anesthesia (TIVA), mean arterial pressure (MAP), intraoperative fentanyl use, postoperative fentanyl dose for intravenous patientcontrolled analgesia (IVPCA), the use of prophylactic antiemetics, the addition of droperidol to postoperative IVPCA, American Society of Anesthesiologists Physical Status (ASAPS), malignancy, and emergency surgery. Additionally, a modified Poisson regression model investigated whether the dose, time, or cumulative effect of $\mathrm{EtCO}_{2}$ affects postoperative nausea two days, vomiting two days, and PONV 3-7 days postoperatively, adjusting for the aforementioned models. To further evaluate the relationship between $\mathrm{EtCO}_{2}$ and PLOS, we performed a linear regression analysis adjusting for the possible covariates in the aforementioned models.

The relationship between intraoperative $\mathrm{EtCO}_{2}$ and PONV may depend on patient and surgical characteristics. Therefore, we performed a subgroup analysis to assess this potential heterogeneity. We used the modified Poisson regression model for the following subgroups: (i) age ( $\geq 50 /<50$ years), (ii) malignancy (yes/no), (iii) smoking history (ever smoked/never smoked), (iv) duration of surgery $(\geq 4 /<4$ hours), (v) TIVA (yes/no), and (vi) the use of intraoperative prophylactic antiemetics (yes/no). We calculated the crude risk ratio of PONV in each subgroup and examined the interaction between subgroups and intraoperative $\mathrm{EtCO}_{2}$.

To maximize statistical power, all eligible patients enrolled in the Kyoto-IMPACT database since 2012, when postoperative nausea and vomiting began to be recorded in their current form, were included in the analysis. To determine the study power, we estimated that approximately 120 laparoscopic gynecologic surgeries were performed annually at Kyoto University Hospital, with 720 surgeries performed over six years. The risk ratio was 1.53 , the incidence of PONV was $40 \%{ }^{4}$, and the proportion of low $\mathrm{EtCO}_{2}$ was $50 \%{ }^{24}$, giving an estimated power of $80 \%$. The rate of missing data was $0.04 \%$, so we conducted a complete case analysis. All statistical tests were two-tailed. We used Stata/SE 15.1 (StataCorp LLC, College Station, Texas, USA) to conduct all statistical analyses.

\section{Results}

\section{Baseline patient characteristics}

Of the 790 patients who underwent laparoscopic gynecologic surgery between 2008 and 2017, 774 met our inclusion criteria, and we included 739 in the complete case analysis (Figure 1). Low EtCO 2 (defined 
as the mean $\mathrm{EtCO}_{2}$ level of less than $35 \mathrm{mmHg}$ ) occurred in 120 patients (16\%), whereas PONV occurred in 430 patients (58\%). Table 1 shows the overall baseline characteristics of the study participants. The median $\mathrm{EtCO}_{2}$ values were $37 \mathrm{mmHg}$ (IQR, 35-40 mmHg) overall, $33 \mathrm{mmHg}(\mathrm{IQR}, 32-34 \mathrm{mmHg})$ in patients with low $\mathrm{EtCO}_{2}$, and $38 \mathrm{mmHg}(\mathrm{IQR}, 36-40 \mathrm{mmHg})$ in patients with normal $\mathrm{EtCO}_{2}$.

\section{Association between low $\mathrm{EtCO}_{2}$ and PONV}

Table 2 shows the study's main results. PONV occurred in 67 (55.83\%) of the 120 patients in the low $\mathrm{EtCO}_{2}$ group, whereas $363(58.64 \%)$ of the 619 patients were in the normal $\mathrm{EtCO}_{2}$ group. We could not find a substantial association between low $\mathrm{EtCO}_{2}$ and PONV (crude risk ratio, $0.95 ; 95 \%$ confidence interval [Cl], $0.80-1.13 ; p=0.577$ ) (adjusted risk ratio, $0.96 ; 95 \% \mathrm{Cl}, 0.80-1.14 ; p=0.658$ ). For further analysis, we divided $\mathrm{EtCO}_{2}$ into quartiles. The second quartile (mean $\mathrm{EtCO}_{2} 35-37 \mathrm{mmHg}$ ) was the reference, and the definition of low $\mathrm{EtCO}_{2}$ was the lowest quartile of mean $\mathrm{EtCO}_{2}$ (mean $\mathrm{EtCO}_{2}$ of less than $35 \mathrm{mmHg}$ ). The second (mean $\mathrm{EtCO}_{2}$ of $35-37 \mathrm{mmHg}$ ), third (mean $\mathrm{EtCO}_{2} 37-40 \mathrm{mmHg}$ ), and fourth (mean $\mathrm{EtCO}_{2} \geq 40 \mathrm{mmHg}$ ) quartiles of mean $\mathrm{EtCO}_{2}$ values were not substantially associated with increased incidence of $\mathrm{PONV}$, with low $\mathrm{EtCO}_{2}$ (first quartile [mean $\mathrm{EtCO}_{2}$ of less than $35 \mathrm{mmHg}$ ) as the reference category.

For the time effects of $\mathrm{EtCO}_{2}$, compared with short-term exposure (first quartile of exposure time to $\mathrm{EtCO}_{2}$ of less than $35 \mathrm{mmHg}, 0-11 \mathrm{~min}$ ), long-term exposure to $\mathrm{EtCO}_{2}$ levels of less than $35 \mathrm{mmHg}$ (fourth quartile of exposure time to $\mathrm{EtCO}_{2}$ of less than $35 \mathrm{mmHg}, 67-613 \mathrm{~min}$ ) was not substantially associated with increased incidence of PONV (crude risk ratio, 1.09; 95\% Cl, 0.91-1.30; $p=0.323$ ) (adjusted risk ratio, $1.03 ; 95 \% \mathrm{Cl}, 0.87-1.22 ; p=0.700)$.

Finally, for the cumulative effects of $\mathrm{EtCO}_{2}$, the fourth quartile of the area under the $\mathrm{EtCO}_{2}$ threshold of 35 $\mathrm{mmHg}(108-2,213)$ was not substantially associated with increased incidence of PONV compared with the first quartile (0-7) (crude risk ratio, 1.08; $95 \% \mathrm{Cl}, 0.91-1.29 ; p=0.346$ ) (adjusted risk ratio, 1.03; $95 \%$ $\mathrm{Cl}, 0.87-1.23 ; p=0.654)$.

\section{Association between low $\mathrm{EtCO}_{2}$ and nausea and vomiting 2 days postoperatively and PONV 3-7 day postoperatively}

The adjusted risk ratio for the low $\mathrm{EtCO}_{2}$ group (mean $\mathrm{EtCO}_{2}$ of less than $35 \mathrm{mmHg}$ ) did not indicate an association between low $\mathrm{EtCO}_{2}$ and nausea and vomiting two days postoperatively or PONV $3-7$ days postoperatively (Table 3 ), with normal $\mathrm{EtCO}_{2}$ being the reference category.

\section{Association between low $\mathrm{EtCO}_{2}$ and PLOS}

The median PLOS was six days (IQR, 5-8 days) (Table 4). The median PLOS in patients with low EtCO was not different from that in patients with normal $\mathrm{EtCO}_{2}$ ( 6 days [IQR, 5-8 days] vs. 6 days (IQR, 5-7 days); $p=0.782$ ). Linear regression analysis showed that low $\mathrm{EtCO}_{2}$ was not likely to be associated with 
PLOS (crude adjusted difference in PLOS , $-0.15 ; 95 \% \mathrm{Cl},-1.29$ to $0.97 ; p=0.783$ ) (adjusted difference in PLOS, $-0.13 ; 95 \% \mathrm{Cl},-1.00$ to $1.28 ; p=0.816)$.

\section{Subgroup analysis}

Subgroup analyses included age ( $\geq 50 /<50$ years), malignancy, smoking history, duration of surgery ( $\geq 4$ hours/ $<4$ hours), TIVA, and the use of intraoperative prophylactic antiemetics. There was no interaction between these variables and PONV (Table 5).

\section{Discussion}

In this retrospective cohort study, intraoperative $\mathrm{EtCO}_{2}$ was not substantially associated with increased incidence of PONV and prolonged PLOS in patients undergoing gynecologic laparoscopic surgery. Furthermore, we examined the effects of the duration and severity of low $\mathrm{EtCO}_{2}$ exposure using the time and cumulative effects of $\mathrm{EtCO}_{2}$ but found no clear association.

Two small studies have studied whether there is an association between low $\mathrm{EtCO}_{2}$ and $\mathrm{PONV}^{17,18}$, but the results have been inconsistent. A randomized controlled trial (RCT) involving 75 patients who underwent percutaneous nephrolithotripsy reported that the hypercapnia management group had less PONV ${ }^{17}$. However, a prospective observational study involving 90 pediatric patients who underwent inguinal surgery has reported that elevated levels of $\mathrm{EtCO}_{2}$ were an independent predictor of PONV ${ }^{18}$. As the aforementioned studies have different types of surgery and patient backgrounds, their results might not be directly applicable to patients undergoing gynecologic laparoscopic surgery.

Furthermore, three studies on patients who had undergone gynecologic surgery have shown inconsistent results. An RCT involving 387 patients who underwent gynecologic laparoscopic surgery reported mild hypercapnia management did not reduce PONV ${ }^{19}$. That study did not evaluate the effects of low $\mathrm{EtCO}_{2}$ (mean $\mathrm{EtCO}_{2}$ level of less than $35 \mathrm{mmHg}$ ). Alternatively, a retrospective cohort study involving 146 patients undergoing open gynecologic surgery has reported that the minimum $\mathrm{EtCO}_{2}$ level of $\leq 31 \mathrm{mmHg}$ lasting longer than 10 min was associated with an increased incidence of PONV ${ }^{16}$. Still, that study only evaluated the effects of extremely low EtCO2 levels (mean EtCO2 of $\leq 31 \mathrm{mmHg}$ ). It did not evaluate the dose and time effects of low EtCO2 below the commonly defined $\mathrm{EtCO}_{2}$ level of $35 \mathrm{mmHg}$. Furthermore, an RCT involving 60 patients undergoing gynecologic laparoscopic surgery reported that low $\mathrm{EtCO}_{2}$ management reduced the incidence of nausea, PONV score, and the use of rescue antiemetics ${ }^{25}$; these results differed from the two aforementioned studies. Management to keep EtCO2 at a low level may avoid PONV by inhibiting cerebral vasodilation, preventing increased intracranial pressure caused by the pneumoperitoneum and Trendelenburg position, which would not affect the ischemia-sensitive vestibular system. However, this study may have an internal validity problem in which it was not blinded. Furthermore, it had a generalizability problem because it excluded patients with severe systemic diseases, ASAPS-III patients, those with a history of PONV motion sickness, and smokers. 
Considering that the results of previous studies are inconsistent, the evidence on the association between intraoperative low $\mathrm{EtCO}_{2}$ and $\mathrm{PONV}$ remains limited. Therefore, we conducted this study, which involved the largest cohort from real-world data, which provided a sufficient sample size, resulting in a statistical power of $80 \%$ to detect a risk ratio of 1.53 . Furthermore, adjusting for important confounders, such as blood pressure, age, and intraoperative fentanyl use, and assessing the dose-effect of low $\mathrm{EtCO}_{2}$ (mean $\mathrm{EtCO}_{2}$ of less than $35 \mathrm{mmHg}$ ) and the effects of the duration and severity of low $\mathrm{EtCO}_{2}$ exposure, we could not demonstrate an association between low $\mathrm{EtCO}_{2}$ and $\mathrm{PONV}$. Even extremely low $\mathrm{EtCO}_{2}$, defined as $\mathrm{EtCO}_{2}$ of less than $31 \mathrm{mmHg}$ sustained for more than 10 minutes $^{16}$, failed to show an association with PONV (Supplemental Data Table S2).

This study has several strengths. First, it investigated the association between the effects of $\mathrm{EtCO}_{2}$ and PONV and PLOS, the dose effects of $\mathrm{EtCO}_{2}$ (mean level of less than $35 \mathrm{mmHg}$ ) and the effects of the duration (time effects, long-term exposure to $\mathrm{EtCO}_{2}$ of less than $35 \mathrm{mmHg}$ ) and severity (cumulative effects, area under the threshold of $\mathrm{EtCO}_{2}$ of less than $35 \mathrm{mmHg}$ ). Among the three previous studies that examined the association between intraoperative low $\mathrm{EtCO}_{2}$ and $\mathrm{PONV}$, which only evaluated the dose effects $19,17,18$, only one study evaluated the association between the time effects of low $\mathrm{EtCO}_{2}$ and PONV ${ }^{16}$. Second, this study adjusted for potential confounding factors that were not adjusted in previous studies, such as blood pressure, age, and intraoperative fentanyl use, using a modified Poisson regression model. Third, this was a large study with sufficient sample size. All previous studies had small sample sizes, so the number of confounding factors that can be adjusted is limited.

This study has several limitations. First, we extracted information on the presence of nausea and vomiting from the records of assessments performed by the ward nurses at least twice a day, so PONV occurring at other times may have been overlooked. However, we thought that moderate to severe PONV reported voluntarily by patients or required treatment was fully measured. Second, we did not consider the $\mathrm{PaCO}_{2}-\mathrm{EtCO}_{2}$ gap to calibrate $\mathrm{EtCO}_{2}$ levels using $\mathrm{PaCO}_{2}$ levels. Thus, we underestimated the effects of low $\mathrm{EtCO}_{2}$ and overestimated the effects of hypercapnia. However, since $\mathrm{PaCO}_{2}$ is usually $2-5 \mathrm{mmHg}$ higher than $\mathrm{EtCO}_{2}$ in healthy populations, this was considered a limited effect. Last, there may be unknown and unmeasured confounding factors, such as potential reasons for anesthesiologists to target a specific $\mathrm{EtCO}_{2}$ level, missing data on intraoperative ventilation parameters, and PONV risk factors among patient factors is, history of PONV and motion sickness.

\section{Conclusion}

Intraoperative low $\mathrm{EtCO}_{2}$ (less than $35 \mathrm{mmHg}$ ) was not substantially associated with either increased incidence of PONV or prolonged PLOS in patients undergoing gynecologic laparoscopic surgery.

\section{Declarations}


Assistance with the study

We are grateful to Mr. Yoshihiro Kinoshita, Ms. Tomoko Hosoya, and Mr. Yohei Taniguchi (Medical Information Systems Section, Management Division, Kyoto University Hospital, Kyoto, Japan) for their assistance in data collection for this study.

\section{Financial support and sponsorship}

This work was supported in part by the Japan Society for the Promotion of Science KAKENHI program (grant number: 20K09242, principal investigator: Toshiyuki Mizota) and the 2019 Kyoto University ISHIZUE Research Development Program (principal investigator: Toshiyuki Mizota).

\section{Conflict of Interest}

The authors have no conflicts of interest.

\section{Ethics approval}

All procedures performed in studies involving human participants were in accordance with the ethical standards of the institutional and/or national research committee and with the 1964 Helsinki Declaration and its later amendments or comparable ethical standards. The Certified Review Board of Kyoto University, Kyoto, Japan (Chairperson Prof. Shinji Kosugi) approved the protocol for this study (approval no.: R1272-3, January 23, 2020). Additionally, the informed consent requirement was waived due to this study's retrospective nature.

\section{Authorship clarified}

Conceptualization: Li Dong

Methodology: Li Dong, Toshiyuki Mizota, Yosuke Yamamoto, Chikashi Takeda, Hajime Yamazaki, Miho Hamada, Akiko Hirotsu

Formal analysis and investigation: Li Dong, Chikashi Takeda, Hajime Yamazaki, Miho Hamada, Akiko Hirotsu, Yosuke Yamamoto, Toshiyuki Mizota

Writing - original draft preparation: Li Dong

Writing - review and editing: Li Dong, Chikashi Takeda, Hajime Yamazaki, Miho Hamada, Akiko Hirotsu, Yosuke Yamamoto, Toshiyuki Mizota

Editing and approval of the manuscript: Li Dong, Chikashi Takeda, Hajime Yamazaki, Miho Hamada, Akiko Hirotsu, Yosuke Yamamoto, Toshiyuki Mizota

Funding acquisition: Toshiyuki Mizota 
Resources: Li Dong,Toshiyuki Mizota

Supervision: Toshiyuki Mizota

\section{References}

1. Pierre, S. \& Whelan, R. Nausea and vomiting after surgery. Continuing Education in Anaesthesia Critical Care \& Pain 13, 28-32, doi:10.1093/bjaceaccp/mks046 (2012).

2. Gan, T. J. et al. Fourth Consensus Guidelines for the Management of Postoperative Nausea and Vomiting. Anesth Analg 131, 411-448, doi:10.1213/ane.0000000000004833 (2020).

3. Apfel, C. C., Läärä, E., Koivuranta, M., Greim, C. A. \& Roewer, N. A simplified risk score for predicting postoperative nausea and vomiting: conclusions from cross-validations between two centers. Anesthesiology 91, 693-700, doi:10.1097/00000542-199909000-00022 (1999).

4. Apfel, C. C. et al. Evidence-based analysis of risk factors for postoperative nausea and vomiting. $\mathrm{Br} \mathrm{J}$ Anaesth 109, 742-753, doi:10.1093/bja/aes276 (2012).

5. Macario, A., Weinger, M., Truong, P. \& Lee, M. Which clinical anesthesia outcomes are both common and important to avoid? The perspective of a panel of expert anesthesiologists. Anesth Analg $\mathbf{8 8}$, 1085-1091, doi:10.1097/00000539-199905000-00023 (1999).

6. Watcha, M. F. \& White, P. F. Postoperative nausea and vomiting. Its etiology, treatment, and prevention. Anesthesiology 77, 162-184, doi:10.1097/00000542-199207000-00023 (1992).

7. Habib, A. S., Chen, Y. T., Taguchi, A., Hu, X. H. \& Gan, T. J. Postoperative nausea and vomiting following inpatient surgeries in a teaching hospital: a retrospective database analysis. Curr Med Res Opin 22, 1093-1099, doi:10.1185/030079906x104830 (2006).

8. Burnum, J. F., Hickam, J. B. \& Mc, I. H. The effect of hypocapnia on arterial blood pressure. Circulation 9, 89-95, doi:10.1161/01.cir.9.1.89 (1954).

9. Pinsky, M. R. Cardiovascular effects of ventilatory support and withdrawal. Anesthesia and analgesia 79, 567-576, doi:10.1213/00000539-199409000-00029 (1994).

10. Guzman, J. A. \& Kruse, J. A. Splanchnic hemodynamics and gut mucosal-arterial PCO(2) gradient during systemic hypocapnia. J Appl Physiol (1985) 87, 1102-1106, doi:10.1152/jappl.1999.87.3.1102 (1999).

11. Burykh, E. A. Interaction of hypocapnia, hypoxia, brain blood flow, and brain electrical activity in voluntary hyperventilation in humans. Neurosci Behav Physio/ 38, 647-659, doi:10.1007/s11055-0089029-y (2008).

12. Takahashi, C. E. et al. Association of intraprocedural blood pressure and end tidal carbon dioxide with outcome after acute stroke intervention. Neurocrit Care 20, 202-208, doi:10.1007/s12028-0139921-3 (2014).

13. Yuzo Teramoto, T. U., Nobuo Nagai, Yumiko Takada, Kazuyuki Ikeda, Akikazu Takada. Plasma levels of 5-HT and 5-HIAA increased after intestinal ischemia/reperfusion in rats. Jpn J Physio/ 48, 9 
(1998).

14. Marston, A. Responses of the splanchnic circulation to ischaemia. J Clin Pathol Suppl (R Coll Pathol) 11, 59-67, doi:10.1136/jcp.s3-11.1.59 (1977).

15. Sarna, G. S., Obrenovitch, T. P., Matsumoto, T., Symon, L. \& Curzon, G. Effect of transient cerebral ischaemia and cardiac arrest on brain extracellular dopamine and serotonin as determined by in vivo dialysis in the rat. J Neurochem 55, 937-940, doi:10.1111/j.1471-4159.1990.tb04581.x (1990).

16. Fujimoto, D., Egi, M., Makino, S. \& Mizobuchi, S. The association of intraoperative end-tidal carbon dioxide with the risk of postoperative nausea and vomiting. J Anesth 34, 195-201, doi:10.1007/s00540-019-02715-4 (2020).

17. Saghaei, M., Matin, G. \& Golparvar, M. Effects of intra-operative end-tidal carbon dioxide levels on the rates of post-operative complications in adults undergoing general anesthesia for percutaneous nephrolithotomy: A clinical trial. Advanced biomedical research 3, 84, doi:10.4103/22779175.127997 (2014).

18. Altay, N., Yalçın, S., Aydoğan, H., Küçük, A. \& Yüce, H. H. Effects of end tidal CO2 and venous CO2 levels on postoperative nausea and vomiting in paediatric patients. Eur Rev Med Pharmacol Sci 19, 4254-4260 (2015).

19. Son, J. S., Oh, J. Y. \& Ko, S. Effects of hypercapnia on postoperative nausea and vomiting after laparoscopic surgery: a double-blind randomized controlled study. Surgical endoscopy 31, 45764582, doi:10.1007/s00464-017-5519-8 (2017).

20. Mizota, T. et al. Invasive Respiratory or Vasopressor Support and/or Death as a Proposed Composite Outcome Measure for Perioperative Care Research. Anesth Analg 129, 679-685, doi:10.1213/ane.0000000000003921 (2019).

21. Mizota, T. et al. Transient acute kidney injury after major abdominal surgery increases chronic kidney disease risk and 1-year mortality. J Crit Care 50, 17-22, doi:10.1016/j.jcrc.2018.11.008 (2019).

22. Way, M. \& Hill, G. E. Intraoperative end-tidal carbon dioxide concentrations: what is the target? Anesthesiol Res Pract 2011, 271539, doi:10.1155/2011/271539 (2011).

23. Zou, G. A modified poisson regression approach to prospective studies with binary data. Am J Epidemiol 159, 702-706, doi:10.1093/aje/kwh090 (2004).

24. Akkermans, A. et al. An observational study of end-tidal carbon dioxide trends in general anesthesia. Canadian journal of anaesthesia = Journal canadien d'anesthesie 66, 149-160, doi:10.1007/s12630018-1249-1 (2019).

25. Besir, A. \& Tugcugil, E. Comparison of different end-tidal carbon dioxide levels in preventing postoperative nausea and vomiting in gynaecological patients undergoing laparoscopic surgery. Journal of Obstetrics and Gynaecology, 1-8, doi:10.1080/01443615.2020.1789961 (2020).

\section{Tables}

Table 1. Patient characteristics $(n=739)$ 


\begin{tabular}{|c|c|c|c|}
\hline Characteristics & $\begin{array}{l}\text { All patients } \\
(n=739)\end{array}$ & $\begin{array}{l}\text { Low } \mathrm{EtCO}_{2} \\
(\mathrm{n}=120)\end{array}$ & $\begin{array}{l}\text { Normal EtCO } \\
(n=619)\end{array}$ \\
\hline Age, years & $45(36-56)$ & $47(34-58)$ & $44(36-55)$ \\
\hline \multicolumn{4}{|l|}{ ASA-PS } \\
\hline 1 & $402(54.55 \%)$ & $60(50.42 \%)$ & $342(55.34 \%)$ \\
\hline II & $322(43.69 \%)$ & $58(48.74 \%)$ & $264(42.72 \%)$ \\
\hline III & $13(1.76 \%)$ & $1(0.84 \%)$ & $12(1.94 \%)$ \\
\hline BMI & $\begin{array}{l}21.28(19.35- \\
23.62)\end{array}$ & $\begin{array}{l}21.73(19.38- \\
24.45)\end{array}$ & $\begin{array}{l}21.16(19.35- \\
23.52)\end{array}$ \\
\hline Malignant & $205(27.74 \%)$ & $25(20.83 \%)$ & $180(29.08 \%)$ \\
\hline Never smoker & $567(76.73 \%)$ & $87(72.50 \%)$ & $480(77.54)$ \\
\hline Emergency surgery & $42(5.70 \%)$ & $6(5.04 \%)$ & $36(5.83 \%)$ \\
\hline Duration of surgery, minute & $186(125-270)$ & $156(110-233)$ & $195(129-276)$ \\
\hline Blood loss, ml & $10(0-100)$ & $0(0-75)$ & $17(0-100)$ \\
\hline Transfusion volume, ml & $0(0)$ & $0(0)$ & $0(0)$ \\
\hline Infusion volume, $\mathrm{ml}$ & $\begin{array}{l}1400(1000- \\
2040)\end{array}$ & $\begin{array}{l}1265(920- \\
1920)\end{array}$ & $\begin{array}{l}1450(1000- \\
2060)\end{array}$ \\
\hline TIVA & $135(18.27 \%)$ & $25(20.83 \%)$ & $110(17.77 \%)$ \\
\hline Mean MAP, mmHg & $73(68-80)$ & $73(68-81)$ & $73(68-80)$ \\
\hline Intraoperative antiemetics use & $284(38.43 \%)$ & $37(30.83 \%)$ & $247(39.90 \%)$ \\
\hline Addition of droperidol in IVPCA & $321(43.44 \%)$ & $38(31.67 \%)$ & $283(45.72 \%)$ \\
\hline $\begin{array}{l}\text { Total intraoperative fentanyl dose } \\
(\mu \mathrm{g})\end{array}$ & $200(150-250)$ & $200(100-250)$ & $200(150-250)$ \\
\hline $\begin{array}{l}\text { Postoperative fentanyl dose in IVPCA } \\
(\mu \mathrm{g} / \mathrm{h})\end{array}$ & $20(0-25)$ & $20(0-25)$ & $20(0-25)$ \\
\hline Mean $\mathrm{EtCO}_{2}$ & $37(35-40)$ & $33(32-34)$ & $38(36-40)$ \\
\hline Minimum $\mathrm{EtCO}_{2}$ & $31(29-33)$ & $28(26-30)$ & $32(30-34)$ \\
\hline Maximum $\mathrm{EtCO}_{2}$ & $42(40-46)$ & $37(36-39)$ & $43(41-47)$ \\
\hline
\end{tabular}

Values are given as median (interquartile range) or count (\%). 
Abbreviations: ASAPS, American Society of Anesthesiologists Physical Status; BMI, body mass index; TIVA, total intravenous anesthesia; MAP, mean arterial pressure; IVPCA, intravenous patient-controlled analgesia; $\mathrm{EtCO}_{2}$, end-tidal carbon dioxide.

Table 2. Multivariable analysis of the relationship between $\mathrm{EtCO}_{2}$ and POD2-PONV 


\begin{tabular}{|c|c|c|c|c|c|c|}
\hline & $\mathbf{N}$ & $\begin{array}{l}\text { POD2- } \\
\text { PONV }\end{array}$ & $\begin{array}{l}\text { Crude } \\
\text { Risk Ratio } \\
(95 \% \mathrm{Cl})\end{array}$ & $P$-value & $\begin{array}{l}\text { Adjusted } \\
\text { Risk Ratio } \\
(95 \% \mathrm{Cl})\end{array}$ & $P$-value \\
\hline \multicolumn{7}{|l|}{ Mean $\mathrm{EtCO}_{2}$} \\
\hline Normal EtCO 2 & 619 & $\begin{array}{l}363 \\
(58.64 \%)\end{array}$ & 1 & - & 1 & - \\
\hline Low $\mathrm{EtCO}_{2}$ & 120 & $\begin{array}{l}67 \\
(55.83 \%)\end{array}$ & $\begin{array}{l}0.95(0.80- \\
1.13)\end{array}$ & 0.577 & $\begin{array}{l}0.96(0.80- \\
1.14)\end{array}$ & 0.658 \\
\hline \multicolumn{7}{|l|}{ Mean $\mathrm{EtCO}_{2}$} \\
\hline$<35 \mathrm{mmHg}$ & 120 & $\begin{array}{l}67 \\
(55.83 \%)\end{array}$ & $\begin{array}{l}1.01(0.82- \\
1.24)\end{array}$ & 0.906 & $\begin{array}{l}1.04(0.85- \\
1.28)\end{array}$ & 0.650 \\
\hline $35-37 \mathrm{mmHg}$ & 171 & $\begin{array}{l}101 \\
(59.06 \%)\end{array}$ & $\begin{array}{l}1.07(0.89- \\
1.27)\end{array}$ & 0.451 & $\begin{array}{l}1.09(0.92- \\
1.30)\end{array}$ & 0.284 \\
\hline $37-40 \mathrm{mmHg}$ & 254 & $\begin{array}{l}155 \\
(61.02 \%)\end{array}$ & $\begin{array}{l}1.10(0.94- \\
1.29)\end{array}$ & 0.217 & $\begin{array}{l}1.15(0.98- \\
1.34)\end{array}$ & 0.079 \\
\hline$\geq 40 \mathrm{mmHg}$ & 194 & $\begin{array}{l}107 \\
(55.15 \%)\end{array}$ & 1 & - & 1 & - \\
\hline \multicolumn{7}{|c|}{ Minutes below $\mathrm{EtCO}_{2} 35 \mathrm{mmHg}$} \\
\hline $\begin{array}{l}\text { Quartile value } 1 \quad(0-11 \\
\text { min) }\end{array}$ & 185 & $\begin{array}{l}102 \\
(55.14 \%)\end{array}$ & 1 & - & 1 & - \\
\hline $\begin{array}{l}\text { Quartile value } 2 \quad(12-25 \\
\text { min) }\end{array}$ & 187 & $\begin{array}{l}106 \\
(56.68 \%)\end{array}$ & $\begin{array}{l}1.02(0.85- \\
1.23)\end{array}$ & 0.764 & $\begin{array}{l}1.04(0.87- \\
1.24)\end{array}$ & 0.653 \\
\hline $\begin{array}{l}\text { Quartile value } 3 \text { (26-66 } \\
\text { min) }\end{array}$ & 181 & $\begin{array}{l}110 \\
(60.77 \%)\end{array}$ & $\begin{array}{l}1.10(0.92- \\
1.31)\end{array}$ & 0.276 & $\begin{array}{l}1.10(0.93- \\
1.30)\end{array}$ & 0.222 \\
\hline $\begin{array}{l}\text { Quartile value } 4 \text { (67- } \\
613 \mathrm{~min})\end{array}$ & 186 & $\begin{array}{l}112 \\
(60.22 \%)\end{array}$ & $\begin{array}{l}1.09(0.91- \\
1.30)\end{array}$ & 0.323 & $\begin{array}{l}1.03(0.87- \\
1.22)\end{array}$ & 0.700 \\
\hline \multicolumn{7}{|c|}{ Area under the threshold of $\mathrm{EtCO}_{2} 35 \mathrm{mmHg}$} \\
\hline Quartile value $1 \quad(0-7)$ & 183 & $\begin{array}{l}98 \\
(53.55 \%)\end{array}$ & 1 & - & 1 & - \\
\hline Quartile value $2 \quad(8-36)$ & 182 & $\begin{array}{l}104 \\
(57.14 \%)\end{array}$ & $\begin{array}{l}1.03(0.86- \\
1.23)\end{array}$ & 0.744 & $\begin{array}{l}1.01(0.85- \\
1.21)\end{array}$ & 0.825 \\
\hline $\begin{array}{l}\text { Quartile value } 3 \\
\text { 107) }\end{array}$ & 186 & $\begin{array}{l}113 \\
(60.75 \%)\end{array}$ & $\begin{array}{l}1.08(0.91- \\
1.29)\end{array}$ & 0.358 & $\begin{array}{l}1.10(0.93- \\
1.30)\end{array}$ & 0.232 \\
\hline $\begin{array}{l}\text { Quartile value } 4 \text { (108- } \\
2213)\end{array}$ & 188 & $\begin{array}{l}115 \\
(61.17 \%)\end{array}$ & $\begin{array}{l}1.08(0.91- \\
1.29)\end{array}$ & 0.346 & $\begin{array}{l}1.03(0.87- \\
1.23)\end{array}$ & 0.654 \\
\hline
\end{tabular}


Abbreviations: $\mathrm{EtCO}_{2}$, end-tidal carbon dioxide; POD 2, postoperative day 2; PONV, postoperative nausea and vomiting; $\mathrm{Cl}$, confidence interval; MAP, mean arterial pressure; IVPCA, intravenous patient-controlled analgesia; BMI, body mass index; ASAPS, American Society of Anesthesiologists Physical Status.

Table 3. Multivariable analysis of the relationship between $\mathrm{EtCO}_{2}$ and secondary outcomes

\begin{tabular}{|c|c|c|c|c|c|}
\hline & Number of Events (\%) & Crude & $P$-value & Adjusted & $P$-value \\
\hline & & Risk Ratio & & Risk Ratio & \\
\hline & & $(95 \% \mathrm{Cl})$ & & $(95 \% \mathrm{Cl})$ & \\
\hline POD2: Postope & ative nausea & & & & \\
\hline Normal $\mathrm{EtCO}_{2}$ & $346 / 619(55.90 \%)$ & 1 & - & 1 & - \\
\hline Low $\mathrm{EtCO}_{2}$ & $66 / 120(55.00 \%)$ & $0.98(0.82-1.17)$ & 0.857 & $0.99(0.82-1.18)$ & 0.916 \\
\hline POD2: Postope & ative vomiting & & & & \\
\hline Normal EtCO 2 & $184 / 619(29.73 \%)$ & 1 & - & 1 & - \\
\hline Low $\mathrm{EtCO}_{2}$ & $37 / 120(30.83 \%)$ & $1.03(0.77-1.39)$ & 0.807 & $1.17(0.88-1.55)$ & 0.264 \\
\hline POD 3-7: PON & & & & & \\
\hline Normal $\mathrm{EtCO}_{2}$ & $383 / 619(61.87 \%)$ & 1 & - & 1 & - \\
\hline Low $\mathrm{EtCO}_{2}$ & $70 / 120(58.33 \%)$ & $0.94(0.80-1.11)$ & 0.480 & $0.95(0.81-1.12)$ & 0.583 \\
\hline
\end{tabular}

Abbreviations: $\mathrm{EtCO}_{2}$, end-tidal carbon dioxide; POD 2, postoperative day 2; POD 3-7, postoperative days 3 to 7; PONV, postoperative nausea and vomiting; Cl, confidence interval; MAP, mean arterial pressure; IVPCA, intravenous patient-controlled analgesia; BMI, body mass index; ASAPS, American Society of Anesthesiologists Physical Status.

Table 4. Multivariable analysis of the relationship between $\mathrm{EtCO}_{2}$ and PLOS 


\begin{tabular}{|c|c|c|c|c|c|c|}
\hline & $\begin{array}{l}\text { Median } \\
\text { (IQR) }\end{array}$ & $\begin{array}{l}P \\
\text { value }\end{array}$ & $\begin{array}{l}\text { Crude } \\
\text { difference in PLOS (95\% } \\
\mathrm{Cl})\end{array}$ & $\begin{array}{l}\mathrm{P}- \\
\text { value }\end{array}$ & $\begin{array}{l}\text { Adjusted } \\
\text { difference in PLOS } \\
(95 \% \mathrm{Cl})\end{array}$ & $\begin{array}{l}P \\
\text { value }\end{array}$ \\
\hline \multicolumn{7}{|c|}{ Length of stay(day) } \\
\hline $\begin{array}{l}\text { Normal } \\
\mathrm{EtCO}_{2}\end{array}$ & $6(5-8)$ & 0.782 & 1 & - & 1 & - \\
\hline Low $\mathrm{EtCO}_{2}$ & $6(5-7)$ & & $-0.15(-1.29$ to 0.97$)$ & 0.783 & $0.13(-1.00$ to 1.28$)$ & 0.816 \\
\hline
\end{tabular}

Abbreviations: $\mathrm{EtCO}_{2}$, end-tidal carbon dioxide; PLOS, postoperative length of stay; IQR, interquartile range; $\mathrm{Cl}$, confidence interval; MAP, mean arterial pressure; IVPCA, intravenous patient-controlled analgesia; BMI, body mass index; ASAPS, American Society of Anesthesiologists Physical Status.

Table 5. Subgroup analyses stratified by patient and operative variable 


\begin{tabular}{|c|c|c|c|c|c|}
\hline & $\mathbf{N}$ & POD2-PONV & $\begin{array}{l}\text { Crude risk ratio } \\
(95 \% \mathrm{Cl}) \text { of low } \mathrm{EtCO}_{2}\end{array}$ & P-value & $\begin{array}{l}\mathrm{P} \text { for } \\
\text { interaction }\end{array}$ \\
\hline Overall & 739 & $430(58.19 \%)$ & $0.95(0.80-1.13)$ & 0.577 & \\
\hline Age(year) & & & & & 0.837 \\
\hline$<50$ & 454 & $246(54.19 \%)$ & $0.96(0.76-1.20)$ & 0.725 & \\
\hline$\geq 50$ & 285 & $184(64.56 \%)$ & $0.91(0.70-1.18)$ & 0.486 & \\
\hline Malignancy & & & & & 0.594 \\
\hline Yes & 205 & $135(65.85 \%)$ & $0.90(0.64-1.26)$ & 0.540 & \\
\hline No & 534 & $295(55.24 \%)$ & $0.98(0.80-1.20)$ & 0.913 & \\
\hline Smoking history & & & & & 0.640 \\
\hline Ever & 172 & $92(53.49 \%)$ & $1.02(0.72-1.45)$ & 0.892 & \\
\hline Never & 567 & $338(59.61 \%)$ & $0.93(0.76-1.14)$ & 0.511 & \\
\hline Duration of surgery $(\mathrm{h})$ & & & & & 0.491 \\
\hline$\geq 4$ & 238 & $148(62.18 \%)$ & $0.87(0.61-1.23)$ & 0.442 & \\
\hline$<4$ & 501 & $282(56.29 \%)$ & $0.99(0.51-1.21)$ & 0.959 & \\
\hline TIVA & & & & & 0.274 \\
\hline Yes & 604 & $369(61.09 \%)$ & $0.91(0.76-1.10)$ & 0.376 & \\
\hline No & 135 & $61(45.19 \%)$ & $1.19(0.77-1.83)$ & 0.428 & \\
\hline Intraoperative antiemetics & & & & & 0.990 \\
\hline Yes & 284 & $168(59.15 \%)$ & $0.95(0.70-1.28)$ & 0.757 & \\
\hline No & 455 & $262(57.58 \%)$ & $0.95(0.77-1.17)$ & 0.666 & \\
\hline
\end{tabular}

Abbreviations: POD 2, postoperative day 2; PONV, postoperative nausea and vomiting; $\mathrm{Cl}$, confidence interval; TIVA, total intravenous anesthesia.

\section{Figures}




\section{Excluded}

- Epidural analgesia( $(n=1)$

- Under 18 years old( $n=3)$

- Postoperative ICU admission(n=12)
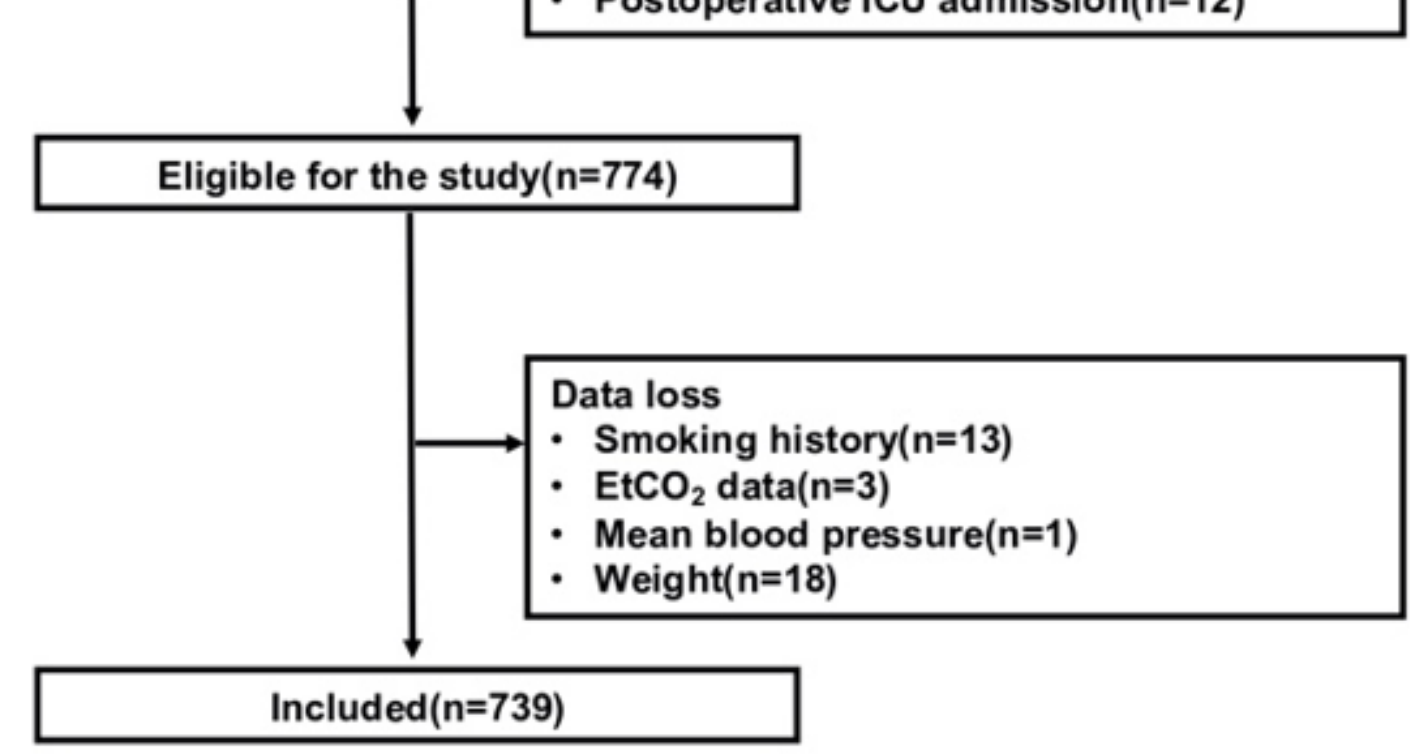

Figure 1

Flowchart of this study

We consecutively included patients aged 18 years or older who underwent laparoscopic gynecologic surgery under general anesthesia at Kyoto University Hospital from 2012 to 2017. Subsequently, cases that met the eligibility criteria were selected and analyzed as complete cases.

\section{Supplementary Files}

This is a list of supplementary files associated with this preprint. Click to download.

- PONVSupplementaldata0131.pdf 